\title{
Estados del ciclo de muda de la jaiba nadadora Ovalipes trimaculatus (de Haan, 1833) basados en observaciones de la morfología externa
}

\author{
Molt cycle stages of the paddle crab Ovalipes trimaculatus (de Hann, 1833) based \\ on observations of the external morphology \\ Javier Alvarez ${ }^{1}$, Christian Véliz ${ }^{1}$ y Jaime Meruane ${ }^{1}$ \\ ${ }^{1}$ Departamento de Acuicultura, Facultad de Ciencias del Mar, Universidad Católica del Norte. Casilla 117, Coquimbo, Chile \\ jalvarezz@ucn.cl
}

\begin{abstract}
The knowledge of molt cycle in crustaceans is important from the physiological point of view and because it can be used in aquaculture and fisheries management. Ten specimens of Ovalipes trimaculatus were held in laboratory under controlled temperature, photoperiod and feeding. A photographic monitoring of the molt cycle was done. We distinguished three external corporal zones that showed significant changes (ecdysial suture, dactyl and base tissues of fifth pereopods). This allowed us to distinguish a scale of five stages of molt cycle. Each stage was described mentioning the evolution of morphological changes from postmolt to ecdysis. The average duration of molt cycle was $76.4 \pm 3.5$ days. The applied methodology causes minimal stress to crabs, thus allowing to observe directly the external morphological changes that occur in corporal zones of crustaceans.
\end{abstract}

Key words: Ecdysis, intermolt, crustaceans
Resumen.- El conocimiento del ciclo de muda en los crustáceos es importante desde el punto de vista fisiológico y porque puede ser aplicado en actividades de acuicultura y manejo pesquero. Diez ejemplares de Ovalipes trimaculatus fueron mantenidos en laboratorio bajo temperatura, fotoperíodo y alimentación controladas. Se realizó un seguimiento fotográfico de los cambios morfológicos ocurridos durante todo el ciclo de muda. Se distinguieron tres zonas corporales externas que mostraron cambios significativos (sutura ecdisial, el dactilopodito y el tejido base del quinto pereiópodo). Esto permitió generar una escala de cinco estados en el ciclo de muda. Cada estado fue descrito señalando los cambios morfológicos desde la postmuda a la ecdisis. La duración promedio del ciclo de muda fue de 76,4 \pm 3,5 días. La metodología aplicada causa un mínimo estrés sobre los ejemplares, permitiendo observar directamente los cambios morfológicos externos que experimentan las zonas y estructuras corporales de estos crustáceos.

Palabras claves: Ecdisis, intermuda, crustáceos

\section{Introducción}

La jaiba nadadora Ovalipes trimaculatus (de Hann, 1833) es una especie cosmopolita y su distribución geográfica se extiende desde Bahía Independencia en el Perú hasta el Canal Trinidad, Chile (Vinuesa 2005), incluyendo la Isla de Juan Fernández (Retamal 1981). También ha sido citada para Argentina, Sudáfrica, Australia y Japón (Vinuesa 2005), sin embargo existe escasa información biológica disponible a pesar de su buena proyección comercial.

El ciclo de muda vincula muchos aspectos de la biología de los crustáceos incluyendo su morfología, fisiología y comportamiento. La ecdisis, que es el desprendimiento del exoesqueleto, permite el crecimiento del crustáceo; es un fenómeno cíclico afectado por un gran número de factores exógenos y endógenos (Hopkins et al. 1999). Para O. trimaculatus no existen registros publicados sobre su ciclo de muda.
Drach $(1939,1944)$ fue el primer autor que entregó una descripción general del ciclo de muda de los crustáceos. Este autor desarrolló una técnica que establece una escala de cinco estados generales dentro de los cuatro grandes períodos del ciclo: estados A y B (período de postmuda), estado $C$ (período intermuda), estado $D$ (período de premuda) y estado E (ecdisis). Este autor basó sus resultados en la observación de los cambios secuenciales del desarrollo de la subcutícula o epidermis y el exoesqueleto (base de las actuales técnicas para determinar los estados del ciclo de muda en crustáceos). Estas técnicas utilizan los cambios en la morfología externa e interna de la epidermis del cuerpo y el desarrollo de las setas que se forman con el nuevo exoesqueleto (Elorza \& Dupré 1996). Sin embargo, en algunas especies de jaibas y otros crustáceos, tanto en juveniles como en adultos, la observación del desarrollo de la epidermis y de las setas se hace dificultoso por el grosor del exoesqueleto, la pigmentación que poseen y la morfología corporal (Miller \& Hankin 2004), obstaculizando la 
determinación de los estados del ciclo de muda bajo la técnica de Drach, haciendo necesario para esto la extracción de muestras de tejido, lo que puede provocar algún daño funcional y estrés elevado sobre los animales (Freeman et al. 1987, Miller \& Hankin 2004).

Actividades productivas como la acuicultura y el manejo pesquero de crustáceos, que usualmente laboran con grandes cantidades de organismos, requieren de una aproximación rápida y confiable del estado de muda de estos animales. Lo anterior hace imprescindible buscar nuevas técnicas que permitan establecer los estados del ciclo de muda o la predicción de la ecdisis con la mínima manipulación posible con el objeto de reducir cualquier tipo de daño y estrés en los crustáceos, aumentando así su supervivencia (Freeman et al.1987, Miller \& Hankin 2004).

En varias especies de crustáceos de importancia comercial se han determinado algunas técnicas de distinción rápida del estado del ciclo de la muda con fines productivos. Peebles (1977) desarrolló una técnica en camarones de cultivo de Macrobrachium rosenbergii, basado en cambios morfológicos externos presentados por el exoesqueleto, Lyle \& MacDonald (1983) aportaron con una técnica rápida para distinguir los estados del ciclo de muda en Panulirus marginatus, pero estos autores modificaron la técnica tradicional, realizando las observaciones del desarrollo setal en los pleópodos, sin la extracción de los mismos. Elorza \& Dupré (1996) agregaron a lo descrito por Drach, cambios morfológicos en el exoesqueleto de Jasus frontalis, una langosta de importancia pesquera y elevado valor económico en Chile, asociando el ablandamiento o descalcificación de algunas placas específicas del exoesqueleto con el desarrollo del ciclo de muda. En la jaiba azul, Callinectes sapidus, se ha utilizado el cambio de color de una zona particular (propodito o propodo) del quinto pereiópodo, distinguiendo las llamadas 'líneas blanca, rosa y roja' de acuerdo al grado de desarrollo del ciclo de muda (Perry et al. 1982, Freeman \& Perry 1985). Freeman et al. (1987) para $C$. sapidus, presentaron una técnica para determinar los estados de muda, sin la remoción de apéndices o secciones de tejido y exoesqueleto para el análisis microscópico. Con el mismo propósito, O’Halloran \& O’Dor (1988) asociaron las observaciones de cambios en las características externas y la alimentación con el desarrollo de las setas en Chionoecetes opilio.

El presente trabajo describe cambios morfológicos externos, desde la postmuda hasta la ecdisis. Si bien estas observaciones permiten asociar sólo indirectamente a los estados tradicionales del ciclo de muda en crustáceos (estados A, B, C y D) (Drach 1939, 1944, Cheng \& Chang
1991, Elorza \& Dupré 1996, Petriella \& Boschi 1997, Reyes \& Lujan 2003, Miller \& Hankin 2004, Promvikorn et al. 2004), son una primera herramienta para distinguir el estado de avance del ciclo de muda en el tiempo, buscando predecir la ecdisis de un modo práctico, con el mínimo de estrés.

\section{Material y métodos}

Diez ejemplares de $O$. trimaculatus de 59,36 $\pm 4,08 \mathrm{~mm}$ de ancho cefalotorácico, fueron recolectado en bahía Tongoy ( $\left.31^{\circ} 15^{\prime} \mathrm{S}, 71^{\circ} 35^{\prime} \mathrm{W}\right)$ y mantenidas en un laboratorio de la Universidad Católica del Norte, en Coquimbo, Chile. Una vez que la ecdisis comenzó, las jaibas fueron marcadas individualmente y separadas, desde el primer día de postmuda (tiempo cero del nuevo ciclo), llevándolas a un estanque independiente de 150 $\mathrm{L}$, a $19 \pm 2^{\circ} \mathrm{C}$ y fotoperíodo de luz/oscuridad de $16 / 8 \mathrm{~h}$. Las jaibas fueron alimentadas ad libitum con trozos de carne de pescado al atardecer y los alimentos no consumidos y excretas fueron extraídos a diario cada mañana.

Las jaibas fueron fotografiadas una vez por semana, a partir de su tiempo cero del ciclo de muda, excepto al final del ciclo, cuando se consideró que estaban cercanas a la ecdisis, en ese momento fueron inspeccionadas y fotografiadas a diario. Las imágenes registraron zonas específicas del cefalotórax, abdomen y de los pereiópodos, en donde se distinguen cambios morfológicos hasta el momento en que las jaibas comienzan la ecdisis.

Las fotografías fueron analizadas en función del tiempo y la permanencia de cada característica morfológica. Se registró la duración del ciclo de muda para cada ejemplar y se estimó un valor promedio del tiempo de duración para el total. Los estados tradicionales de muda con respecto a la descripción de los cambios morfológicos externos e internos fueron establecidos de acuerdo a los estados del ciclo de muda otorgados por Drach (1939).

\section{Resultados}

\section{Desarrollo del ciclo de muda}

El análisis fotográfico permitió distinguir tres zonas corporales que mostraron cambios morfológicos externos significativos, como indicadores del desarrollo del ciclo de muda: i) La línea epimeral o sutura ecdisial; ii) el tejido base del quinto par de pereiópodos (tejido que une la coxa con el cuerpo); iii) el dactilopodito (apéndice remador) del quinto par de pereiópodo (Fig. 1). 

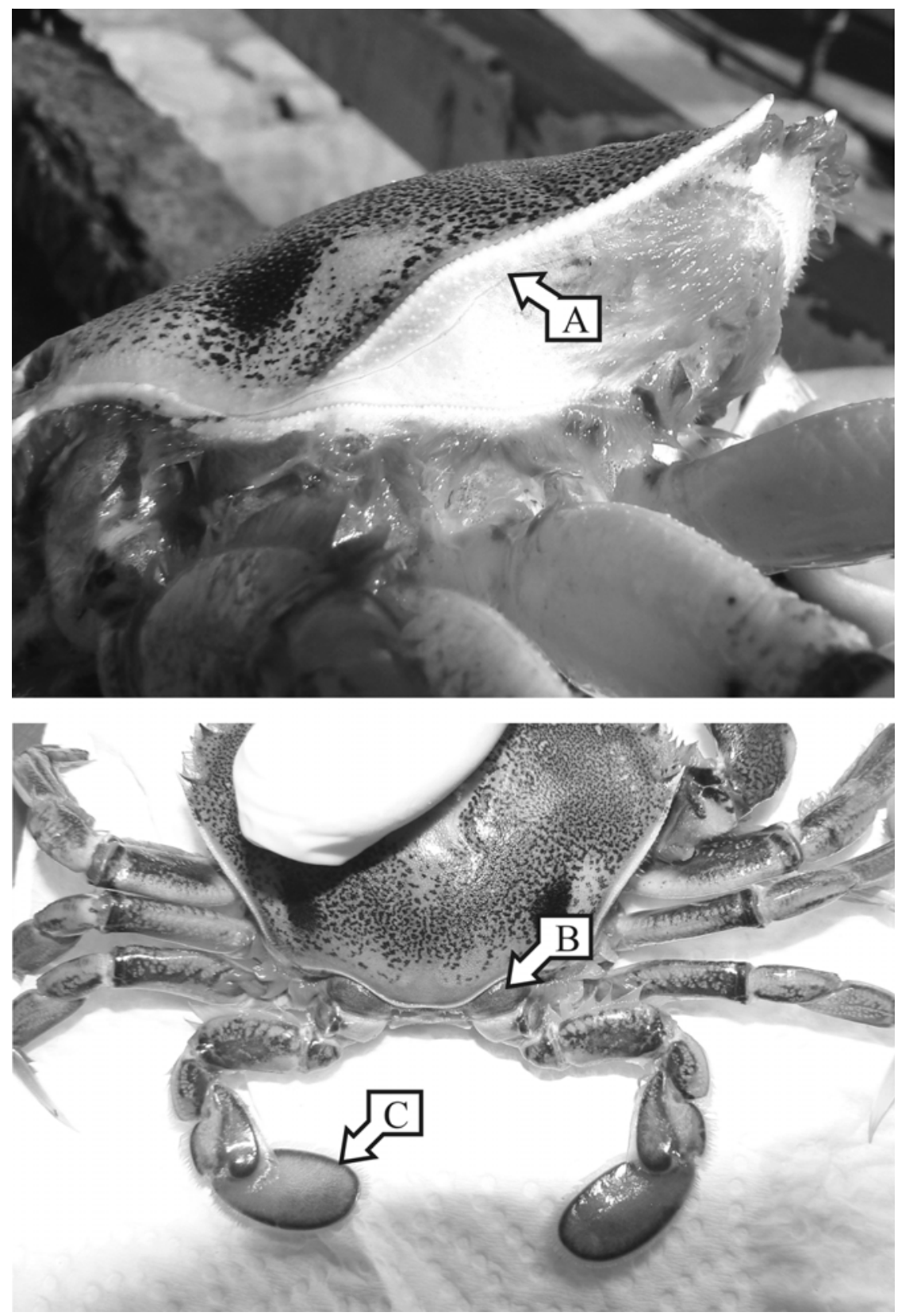

Figura 1

Zonas del cuerpo de $\boldsymbol{O}$. trimaculatus mostrando cambios morfológicos significativos, durante el ciclo de muda. A= Línea epimeral o sutura ecdisial, $B=$ Tejido base del quinto par de pereiópodos, $C=$ Dactilopodito del quinto par de pereiópodos

Corporal zones showing significant morphological changes during of molt cycle in O. trimaculatus. A= Epimeral line or ecdysial suture, $\mathrm{B}=$ Base tissue of fifth pereopod, $\mathrm{C}=$ Dactyl of fifth pereopod 

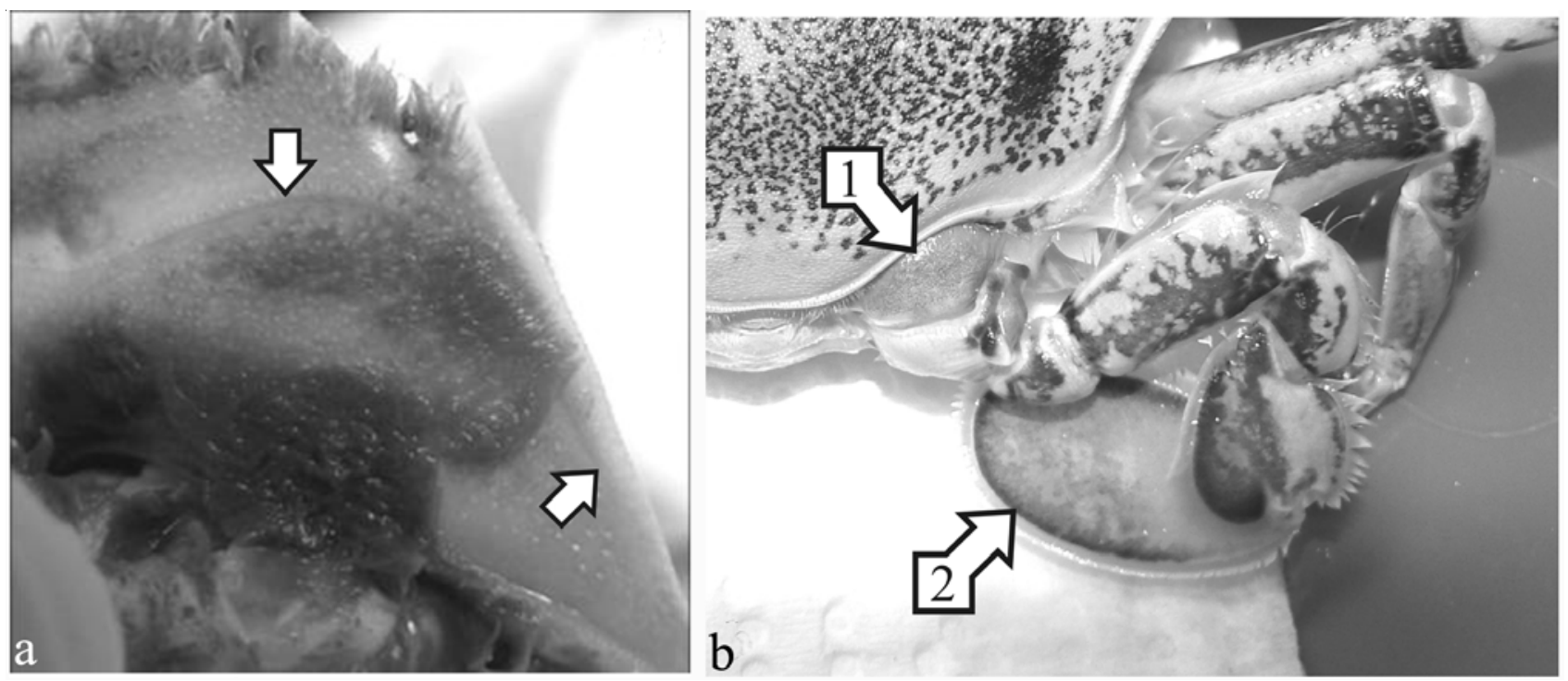

Figura 2

Estado 0 del ciclo de muda de $O$. trimaculatus. a) Sutura ecdisial (flechas). b) Quinto pereiópodo, 1= tejido base y 2= dactilopodito

Molt cycle, Stage 0 in O. trimaculatus. a) Ecdysial suture (arrows). b) Fifth pereopod, 1= base tissue and 2= dactyl

Con el desarrollo temporal de los cambios morfológicos externos de las jaibas en el ciclo de la muda, se generó una escala de cinco estados:

Estado 0: Comienza inmediatamente después que el animal ha finalizado la ecdisis y ha comenzado el endurecimiento de su nuevo exoesqueleto. En este estado, la línea de sutura del cefalotórax se muestra suavemente marcada, distinguida por una leve diferenciación de color más claro que el resto del cefalotórax que la circunda (Fig. 2a). Cuerpo blando, con un endurecimiento paulatino. El endurecimiento del nuevo exoesqueleto comienza entre 2 y $8 \mathrm{~h}$ después de la ecdisis y su máxima extensión es de $72 \mathrm{~h}$, alcanzando el endurecimiento total del cuerpo entre 5 a 11 días.

Los tejidos bases del quinto par de pereiópodos muestran una coloración amarilla clara, con presencia de manchas granulares dispersas de tonalidad café y el tejido se presenta fláccido al tacto (Fig. 2b). El dactilopodito del quinto pereiópodo ('paddle') posee tonalidades de color violeta claro. Existe una línea delgada que marca el borde del dactilopodito con una tonalidad violeta; esta coloración se difumina suavemente hacia el centro del podio (Fig. 2b).

Estado 1: Desde la zona posterior del cefalotórax, la línea de sutura aparece como un surco suavemente marcado con gran diferenciación que se puede observar en forma precisa en el cuerpo de la jaiba con aspecto consistente y sólido (Fig. 3).

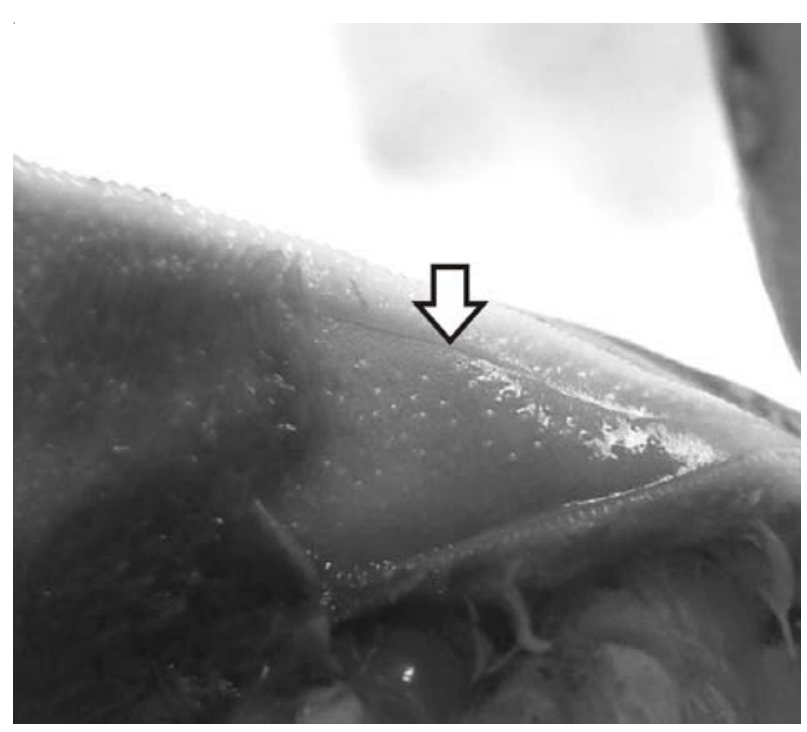

Figura 3

Estado 1 del ciclo de muda de $O$. trimaculatus. Condición de la sutura ecdisial (flecha)

Molt cycle, Stage 1 in O. trimaculatus. Condition of ecdysial suture (arrow) 

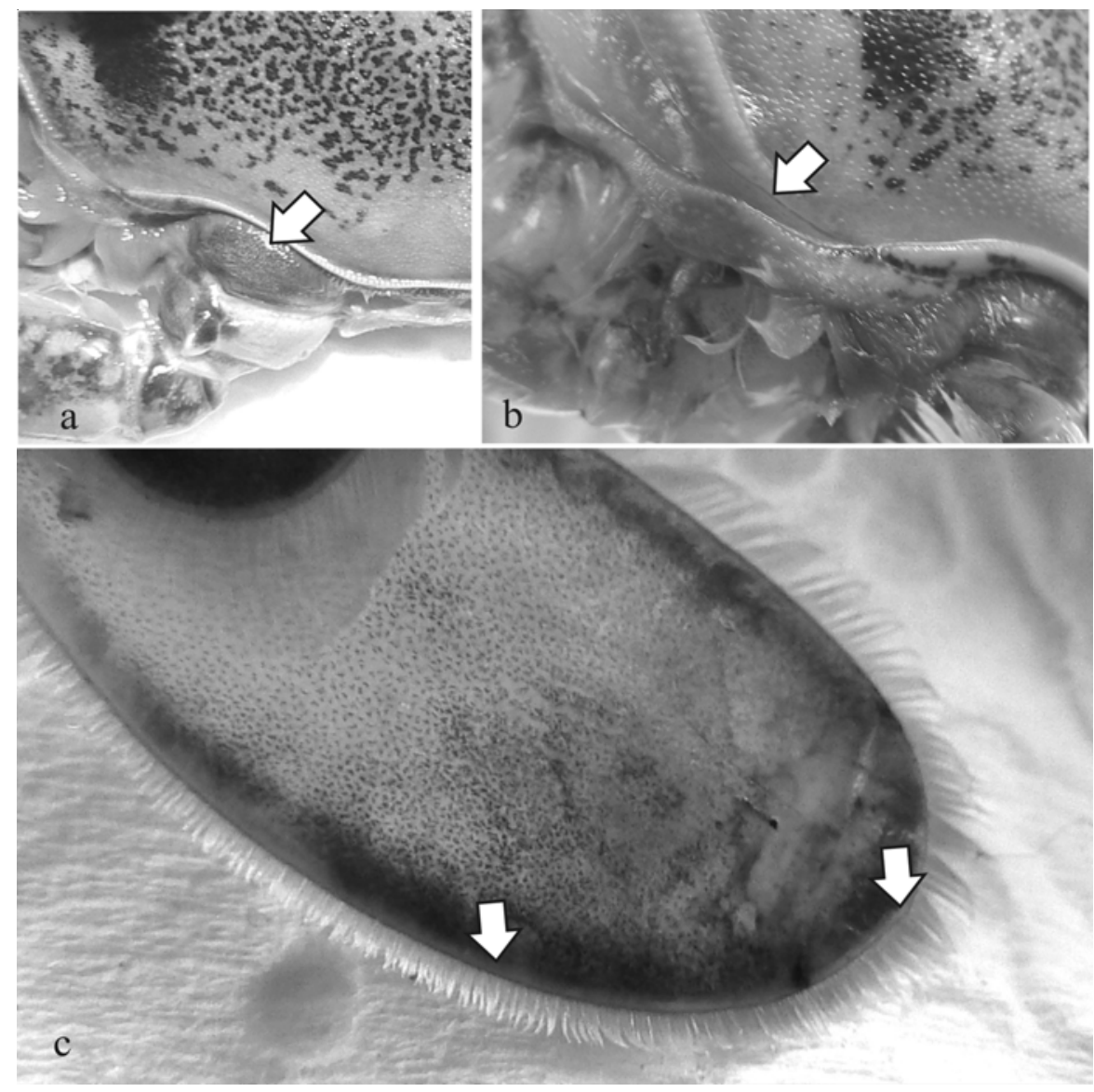

Figura 4

Estado 2 del ciclo de muda de $\boldsymbol{O}$. trimaculatus. a) Tejido base del quinto par de pereiópodos (flecha), b) Área posterior de la sutura ecdisial (candados) (flecha), c) Dactilopodito del quinto par de pereiópodos donde se destaca la separación del tejido (apólisis) (flechas)

Molt cycle, Stage 2 in O. trimaculatus. a) Base tissue of the fifth pereopod (arrow), b) Posterior zone of ecdysial suture (locks) (arrow), c) Dactyl of the fifth pereopod showing the tissue detachment (apolysis) (arrows)

Los tejidos bases del quinto par de pereiópodos no sufren cambios y se mantienen con la misma apariencia que en el Estado 0. El dactilopodito del quinto pereiópodo mantiene sus condiciones anteriores, destacándose sólo la aparición de cromatóforos violetas que comienzan a expandirse a través de la zona central del podio.

Estado 2: Los tejidos bases del quinto par de pereiópodos se comienzan a oscurecer, tornándose grises y aumentando su turgencia al tacto (Fig. 4a). La línea de sutura se muestra en forma de un surco profundo, desde la zona donde termina la sutura ecdisial en la parte posterior del cefalotórax denominada 'candados' (Fig. 4b). La profundidad del surco en la línea de sutura y en los candados comienza a ser un indicador importante del avance del ciclo de muda,
El dactilopodito del quinto par de pereiópodos también sufre cambios, comenzando a mostrar una coloración violeta intensa que delimita notoriamente el borde del podio, diferenciándose claramente del centro de éste. Además es posible observar una leve separación de tejidos en el límite externo del dactilopodito (Fig. 4c).

Estado 3: La línea de sutura se triza. El quiebre comienza desde la zona posterior del cuerpo hacia la zona anterior y hasta el nivel de las espinas laterales del cefalotórax. A medida que transcurre esta etapa, es muy evidente el avance y profundidad de la fractura de la línea epimeral (Fig. 5a). En el sector de los candados, el quiebre ocurre al final de esta etapa.

Los tejidos bases del quinto par de pereiópodos se mantienen de color gris y turgente al tacto. El 

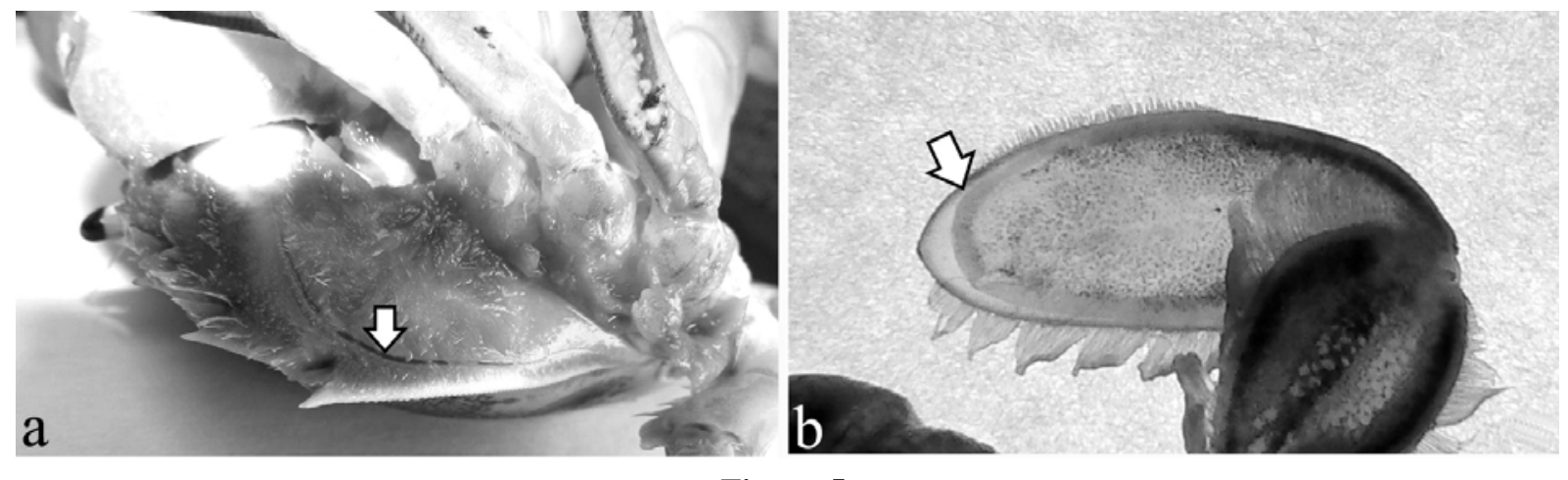

Figura 5

Estado 3 del ciclo de muda de $\boldsymbol{O}$. trimaculatus. a) Sutura ecdisial fracturada, b) Detalle de la formación de un nuevo apéndice Molt cycle, Stage 3 in O. trimaculatus. a) Broken ecdysial suture, b) Detail in development of a new paddle
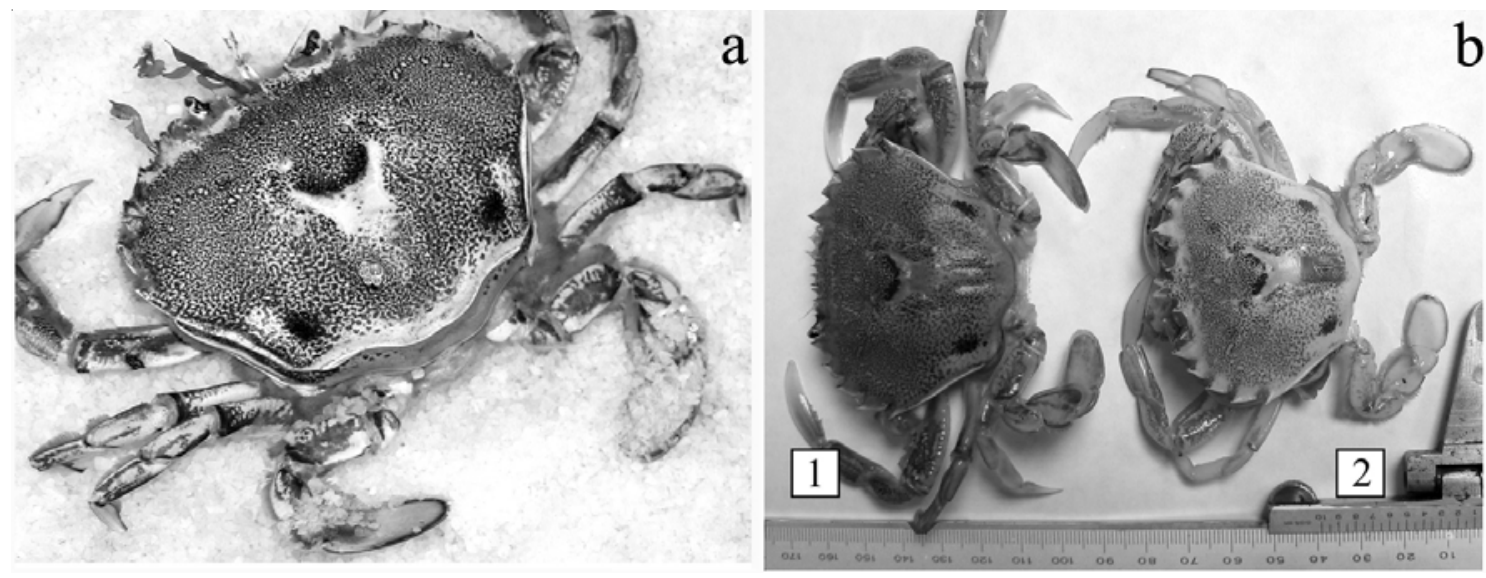

Figura 6

Estado 4 del ciclo de muda o ecdisis de $O$. trimaculatus. a) Rompimiento de los candados, b) Ecdisis. 1) ejemplar mudado y 2) muda

Molt cycle, Stage 4 or ecdisis in O. trimaculatus. a) Broken locks, b) Ecdysis. 1) molt crab and 2) old carapace (shedding)

dactilopodito remador del quinto par de pereiópodos, marca la separación de tejidos en el límite externo del podio. La coloración de la línea violeta que bordea el dactilopodito, se hace más intensa y el resto con una suave coloración en el mismo tono. Bajo algunas condiciones se puede observar claramente la formación de un nuevo segundo podio anticipando la ecdisis (Fig. 5b), indicando que esta zona sería apta para el seguimiento del desarrollo setal.

Estado 4: En este estado ocurre la ecdisis. Esta última etapa comienza con el rompimiento de los candados (Fig. $6 a)$, que marca el inicio de la ecdisis. La parte superior del cefalotórax comienza paulatinamente a levantarse y se separa de la nueva epidermis que posteriormente se endurecerá formando el nuevo exoesqueleto. El cuerpo de la jaiba comienza a elevarse y se separa del antiguo caparazón, los pereiópodos son retirados y la jaiba se libera (Fig. 6b).

\section{Duración del ciclo de muda y comparación con los estados de Drach}

El ciclo de muda bajo las condiciones de laboratorio fue de 76,4 \pm 3,5 días. La duración de cada estado se muestra en la Fig. 7. El Estado 1 fue el que presentó una mayor duración con 23,1 \pm 6,6 días, los Estados 0, 2 y 3 tuvieron una duración de 15,4 \pm 3,0; 18,9 \pm 4,7 y 17,7 \pm 3,5 días respectivamente (Tabla 1). El Estado 4 fue el más corto con sólo 1,3 \pm 0,6 días, finalizando con la ecdisis. 


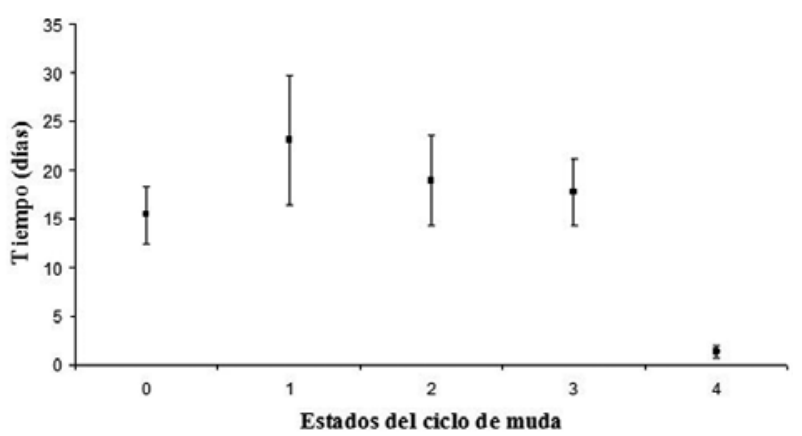

Figura 7

Duración de cada estado del ciclo de muda en O. trimaculatus

Duration of each molt cycle stage in O. trimaculatus

El Estado 0 es comparable a las etapas tradicionales A, B y C temprano determinados por Drach (1939), así como el Estado 1 y 2 a las etapas C y D temprana ( $\left.D_{0}\right)$ respectivamente (Tabla 1). El Estado 3, fue asociado a la etapa D y el Estado 4 correspondió a la ecdisis (etapa E).

\section{Discusión}

Durante el ciclo de muda en los crustáceos decápodos los cambios morfológicos externos son los que resultan fáciles de reconocer. La principal aplicación de reconocer algún estado del ciclo de muda es en el ámbito de la acuicultura y la pesquería, ya que permite la caracterización del crecimiento, procesos reproductivos y captura o cosecha deseada, lo que en consecuencia permite un mejor manejo del recurso. Muchos autores han destacado y enfocado sus investigaciones a reconocer estos cambios en el desarrollo del ciclo de muda (Peebles 1977, Lyle \& MacDonald 1983, Freeman et al. 1987). El presente trabajo ha presentado los cambios morfológicos significativos que ocurren durante el ciclo de muda de $O$. trimaculatus, a través de una escala particular desarrollada para estos cambios. Esta clasificación del ciclo de muda, basada en cambios morfológicos externos, permitiría en términos generales y apoyados en diferentes autores (Haefner \& Van Angel 1975, Peebles 1977, Lyle \& MacDonald 1983, Freeman et al. 1987, O’Halloran \& O’Dor 1988) llegar a tener una aproximación a la escala tradicional de Drach, permitiendo reconocer los períodos

Tabla 1

Estados del ciclo de muda de $\boldsymbol{O}$. trimaculatus en relación a lo descrito para los estados de Drach

Stages of molt cycle of $O$. trimaculatus in correlation to description of Drach's stages

\begin{tabular}{|c|c|c|c|c|c|c|}
\hline $\begin{array}{l}\text { Estados del } \\
\text { ciclo de muda }\end{array}$ & $\begin{array}{l}\text { Duración de los } \\
\text { estados (dias) }\end{array}$ & $\begin{array}{l}\text { Estados } \\
\text { de Drach }\end{array}$ & Período & Cambios morfológicos externos destacados & $\begin{array}{l}\text { Relaciones con otras } \\
\text { investigaciones }\end{array}$ & Referencias \\
\hline 0 & $15,4 \pm 3,0$ & $\begin{array}{l}\text { A, B y C } \\
\text { temprana }\end{array}$ & Postmuda & $\begin{array}{l}\text { - Sutura ecdisial suavemente marcada } \\
\text { - Jaiba blanda hacia un endurecimiento gradual } \\
\text { - Tejidos bases quinto pereiópodo con } \\
\text { coloración amarillo claro y flácidos al tacto }\end{array}$ & $\begin{array}{l}\text { - Jaiba blanda real, con las espinas } \\
\text { del exoesqueleto maleables } \\
\text { - Jaiba piel de cuero, papel y } \\
\text { comienzo del endurecimiento } \\
\text { - Sutura ecdisial sin marcar }\end{array}$ & $\begin{array}{l}\text { Peebles } 1977 \\
\text { Chan et al. } 1988 \\
\text { O'Halloran \& O'Dor } 1988 \\
\text { Elorza \& Dupré } 1996 \\
\text { Musgrove } 2000 \\
\text { Reyes \& Lujan } 2003\end{array}$ \\
\hline 1 & $23,1 \pm 6,6$ & $\mathrm{C}$ & Intermuda & $\begin{array}{l}\text { Jaiba dura } \\
\text { Sutura ecdisial como un surco suavemente } \\
\text { marcado }\end{array}$ & - Jaiba dura & $\begin{array}{l}\text { O'Halloran \& O'Dor } 1988 \\
\text { Pratoomchat et al. } 2002 \\
\text { Miller \& Hankin } 2004\end{array}$ \\
\hline 2 & $18,9 \pm 4,7$ & $\begin{array}{c}\text { C final } \\
y \\
\text { D temprana }\end{array}$ & $\begin{array}{l}\text { Final de } \\
\text { intermuda } \\
\begin{array}{c}\text { y } \\
\text { comienzo } \\
\text { premuda }\end{array}\end{array}$ & $\begin{array}{l}\text { - Sutura ecdisial como un surco profundo } \\
\text { - Tejidos bases comienzan a oscurecerse } \\
\text { tomando una coloración gris y se vuelven } \\
\text { turgentes } \\
\text { - Dactilopodito aumenta la coloración en el } \\
\text { borde y muestra una separación de tejidos } \\
\text { (apólisis) }\end{array}$ & $\begin{array}{l}\text { Apólisis } \\
\text { - Doble borde en apéndices } \\
\text { examinados con (epidermis } \\
\text { comienza a retraerse desde los } \\
\text { puntos cuticulares de contacto) }\end{array}$ & $\begin{array}{l}\text { Peebles } 1977 \\
\text { O'Brien \& Skinner } 1990 \\
\text { Hopkins et al. } 1999\end{array}$ \\
\hline 3 & $17,7 \pm 3,5$ & $\mathrm{D}$ & Premuda & $\begin{array}{l}\text { - Sutura ecdisial trizada } \\
\text { - Tejidos bases de color gris y turgentes al tacto } \\
\text { - Fuerte color violeta en el borde del } \\
\text { dactilopodito y separación evidente de los } \\
\text { tejidos (algunas veces puede observarse la } \\
\text { formación de un nuevo apéndice dentro del } \\
\text { dactilopodito) }\end{array}$ & $\begin{array}{l}\text { - Descalcificación de la sutura } \\
\text { ecdisial y el cefalotórax } \\
\text { - Aumento de la pigmentación }\end{array}$ & $\begin{array}{l}\text { Haefner \& Van Angel } 1975 \\
\text { Freman et al. } 1987 \\
\text { O'Halloran \& O'Dor, } 1988 \\
\text { Elorza \& Dupré } 1996 \\
\text { Musgrove } 2000\end{array}$ \\
\hline 4 & $1,3 \pm 0,6$ & $\mathrm{E}$ & Ecdisis & $\begin{array}{l}\text { - Ecdisis } \\
\text { - La jaiba se desprende (muda) del antiguo } \\
\text { exoesqueleto }\end{array}$ & $\begin{array}{l}\text { - Ecdisis } \\
\text { - La jaiba se desprende (muda) del } \\
\text { antiguo exoesqueleto }\end{array}$ & O'Halloran \& O'Dor 1988 \\
\hline
\end{tabular}


del ciclo de muda sin desarrollar la extracción de tejidos en los animales.

Freeman et al. (1987) mencionan que la morfología aplanada de la exocutícula y endocutícula del dactilopodito del quinto pereiópodo de Callinectes sapidus, permite la observación de la retracción de tejido y desarrollo setal con una relativa baja magnificación óptica. En el presente estudio, proponemos lo mismo para O. trimaculatus, identificando esta zona como óptima para el seguimiento del desarrollo setal, de tal forma que permita establecer con mucho más detalle los estados tradicionales de la muda. En juveniles de O. trimaculatus es necesario el uso de un instrumento óptico simple para observar las estructuras señaladas por Freeman et al. (1987).

Los resultados alcanzados son relevantes para el manejo de las poblaciones y para la optimización de actividades de acuicultura de esta especie. Por un lado, la observación del tejido y desarrollo setal en el dactiolopodito del quinto par de pereiópodos provoca una mínima intervención y estrés sobre las jaibas. Por otro lado, utilizando los resultados de este estudio se pueden sugerir medidas de manejo tendientes a prohibir la extracción de ejemplares hembras y machos en Estado 3, que se encuentran próximos a mudar, ayudando a la conservación del recurso, sobre todo en hembras dada la estrecha relación que existe entre la muda y las actividades reproductivas en jaibas. Actualmente la única medida de manejo asociada a esta especie está relacionada con la prohibición de extracción de hembras ovígeras.

Además, en actividades de acuicultura se hace imprescindible la sincronización de la muda de las jaibas en cultivo, para evitar canibalismos y competencia por el alimento entregado, en relación a la diferencias de tallas en los estanques o sistemas de cría. Reconocer rápidamente el estado de muda en que se encuentren las jaibas, permitiría implementar actividades operativas tendientes a separar los animales de acuerdo al estado de muda o tiempo restante a la ecdisis.

En este trabajo se pudieron definir claramente cinco estados de desarrollo del ciclo de muda y correspondería al primer registro de una estimación de la duración del ciclo de muda, bajo condiciones de laboratorio, para $O$. trimaculatus. La duración total del ciclo de muda de la jaiba nadadora fue de 76,4 \pm 3,7 días. Las condiciones otorgadas en laboratorio permitieron mantener a las jaibas bajo parámetros de temperatura y fotoperíodo estival, lo que podría indicar que esta estimación de tiempo puede ser usada como una referencia para las condiciones de verano en las jaibas silvestres. Sin embargo, dado que la oferta alimenticia fue controlada en el laboratorio, existe una alta probabilidad que el ciclo de muda, para jaibas silvestres de similares tallas, durante la misma época, sea más extensa que el registrado en este trabajo. A este respecto, se ha mencionado la relación que existe entre la duración del ciclo de muda y los factores ambientales del hábitat, así como las tallas de los animales (Weis 1976, Vega et al. 2006).

El reconocimiento de los cambios morfológicos externos de $O$. trimaculatus durante el ciclo de muda realizados en este trabajo, permitiría tener una buena aproximación a los estados tradicionales de muda descritos por Drach (1939), pero con una técnica de observación no invasiva y sin manipulación del tejido interno y del desarrollo setal. La clasificación establecida en este trabajo es una herramienta práctica para ser aplicada en actividades productivas y de manejo de esta especie, causando un mínimo estrés y daño en los animales. Permite además, establecer una correlación entre los cambios morfológicos y los estados del ciclo de muda con el objetivo de predecir la ecdisis.

\section{Agradecimientos}

Los autores agradecen a los evaluadores anónimos que contribuyeron con sus valiosos comentarios y sugerencias en la redacción del manuscrito final. Esta investigación fue financiada a través del proyecto FONDEF D04I 1410.

\section{Literatura citada}

Chan S, S Rankin \& L Keeley. 1988. Characterization of the molt stages in Penaeus vannamei: Setogenesis and hemolymph levels of total protein, ecdysteroids, and glucose. The Biological Bulletin 175: 185-192.

Cheng J \& ES Chang. 1991. Ecdysteroid treatment delays ecdysis in lobster Homarus americanus. The Biological Bulletin 181: 169-174.

Drach P. 1939. Mue et cycle d'intermue chez les crustacés décapodes. Annales de l'Institut Oceanographique 19: 103391.

Drach P. 1944. Étude préliminaire sur le cycle d'intermue et son conditionnement hormonal chez Leander serratus (Pennant). Bulletin Biologique de la France et de la Belgique 78: 40-62.

Elorza A \& E Dupré. 1996. Determinación de los estados del ciclo de muda de la langosta de Juan Fernández (Jasus frontalis Milne Edwards, 1837). Investigaciones Marinas 24: 67-76.

Freeman JA \& HM Perry. 1985. The crustacean molt cycle and hormonal regulation: Its importance in soft shell blue crab production. En: Perry HM \& RF Malone (eds). Proceedings of the national symposium on the soft-shelled blue crab fishery, pp. 1-12. Biloxi, Mississippi. 
Freeman JA, G Kilgus, D Laurendeau \& HM Perry. 1987. Postmolt and intermolt molt cycle stages of Callinectes sapidus. Aquaculture 61: 201-209.

Haefner PA \& WA van Angel. 1975. Aspects of molting, growth and survival of male rock crabs, Cancer irroratus, in Chesapeake Bay. Chesapeake Science 16(4): 253-265.

Hopkins PM, ACK Chung \& DS Durica. 1999. Limb regeneration in the fiddler crab, Uca pugilator: Histological, physiological and molecular considerations. American Zoology 39: 513-526.

Lyle WG \& CD MacDonald. 1983. Molt stage determination in the Hawaiian spiny lobster Panulirus marginatus. Journal of Crustacean Biology 3(2): 208-216.

Miller TW \& DG Hankin. 2004. Descriptions and durations of premolt setal stages in females Dungeness crabs, Cancer magister. Marine Biology 144: 101-110.

Musgrove RJ. 2000. Molt staging in the southern rock lobster Jasus edwardsii. Journal of Crustacean Biology 20(1): 44-53.

O’Brien JJ \& DM Skinner. 1990. Overriding of the molt-inducing stimulus of multiple limb autotomy in the mud crab Rhithropanopeus harrisii by parasitization with a rhizocephalan. Journal of Crustacean Biology 10(3): 440-445.

O’Halloran MJ \& RK O’Dor. 1988. Molt cycle of male snow crabs, Chionoecetes opilio, from observations of external features, setal changes, and feeding behaviour. Journal of Crustacean Biology 8(2): 164-176.

Peebles JB. 1977. A rapid technique for molt staging in live Macrobrachium rosenbergii. Aquaculture 12: 179-180.

Perry HM, JT Ogle \& L Nicholson. 1982. The fishery for soft crabs with emphasis on the development of a closed recirculating seawater system for shedding crabs. In: Perry HM \& WA van Engel (eds). Proceedings of the blue crab Colloquium 7: 137-152, Biloxi, Mississippi.
Petriella AM \& EE Boschi. 1997. Crecimiento en crustáceos decápodos: Resultados de investigaciones realizadas en Argentina. Investigaciones Marinas 25: 135-157

Pratoomchat B, P Sawangwong, $R$ Guedes, $M$ de Lourdes \& J Machado. 2002. Cuticle ultrastructure changes in the crab Silla serrata over the molt cycle. Journal of Experimental Zoology 293: 414-426.

Promwikorn W, P Kirirat \& P Thaweethamsewee. 2004. Index of molt staging in the black tiger shrimp (Penaeus monodon). Songklanakarin Journal of Science and Technology 26(5): 765-772.

Retamal MA. 1981. Catálogo ilustrado de crustáceos decápodos de Chile. Gayana Zoología 44: 1-110.

Reyes WE \& H Lujan. 2003. Estados y subestados del ciclo de muda del camarón de río (Cryphiops caementarius Molina, 1872) (Crustacea: Decapoda: Palaemonidae). II Congreso Iberoamericano Virtual de Acuicultura, España, pp. 808-817. [en línea] <http://www.civa2003.org>

Vega F, E Cortés, M García \& A Cupul. 2006. Contribución al estudio de la muda y crecimiento de Callinectes arcuatus en Baja California Sur (México), como base para la producción de jaiba suave. IV Congreso Iberoamericano Virtual de Acuicultura, España, pp. 514-521. [en línea] $<$ http://www.civa2006.org>

Vinuesa JH. 2005. Distribución de crustáceos decápodos y estomatópodos del golfo San Jorge, Argentina. Revista de Biología Marina y Oceanografía 40(1): 7-21.

Weis JS. 1976. Effects of environmental factors on regeneration and molting in fiddler crabs. The Biological Bulletin 150: 152-162. 